\title{
Erratum to: Successful treatment of azole-resistant Candida spondylodiscitis with high-dose caspofungin monotherapy
}

\author{
Theodoros Kelesidis · Sotirios Tsiodras
}

Published online: 13 January 2013

(C) Springer-Verlag Berlin Heidelberg 2013

Erratum to: Rheumatol Int (2012) 32:2957-2958

DOI 10.1007/s00296-011-2121-6

The authors' given and family names were published incorrectly in the original publication of the article. They were inadvertently swapped. The complete author group is listed as Theodoros Kelesidis and Sotirios Tsiodras.

The online version of the original article can be found under doi:10.1007/s00296-011-2121-6.

T. Kelesidis $(\square)$

Department of Medicine, Division of Infectious Diseases,

David Geffen School of Medicine at UCLA,

10833 Le Conte Ave. CHS 37-121, Los Angeles

CA 90095, USA

e-mail: tkelesidis@mednet.ucla.edu

\section{S. Tsiodras}

Fourth Department of Internal Medicine,

Attikon University Hospital,

University of Athens Medical School,

Athens, Greece 